\title{
Diagnoses and Procedures of Inpatients with Female Genital Mutilation/Cutting in Swiss University Hospitals: A Cross- Sectional Study
}

Mathilde Horowicz ( $\square$ mathilde.h@bluewin.ch)

University of Geneva Faculty of Medicine: Universite de Geneve Faculte de Medecine

\section{Sara Cottler-Casanova}

Swiss Tropical and Public Health Institute: Schweizerisches Tropen- und Public Health-Institut

Jasmine Abdulcadir

University Hospitals of Geneva Department of Women-Children-Teenagers: Hopitaux Universitaires de Geneve Departement de la Femme de l'Enfant et de l'Adolescent

\section{Research Article}

Keywords: Female genital mutilation, female genital cutting, female genital mutilation/cutting, international classification of diseases, ICD, coding, Switzerland

Posted Date: December 28th, 2021

DOl: https://doi.org/10.21203/rs.3.rs-1162682/v1

License: (우 (i) This work is licensed under a Creative Commons Attribution 4.0 International License. Read Full License 


\section{Abstract}

Background: Female genital mutilation/Cutting (FGM/C) can result in short and long-term complications, which can impact physical, psychological and sexual health. Our objective was to obtain descriptive data about the most frequent health conditions and procedures associated with FGM/C in Swiss university hospitals inpatient women and girls with a diagnosis of FGM/C. Our research focused on the gynaecology and obstetrics departments.

Methods: We conducted an exploratory descriptive study to identify the health outcomes of women and girls with a coded FGM/C diagnose who had been admitted to Swiss university hospitals between 2016 and 2018. Four of the five Swiss university hospitals provided anonymized data on primary and secondary diagnoses coded with the International Classification of Diseases (ICD) and interventions coded in their medical files.

Results: Between 2016 and 2018, 207 inpatients had a diagnosis of FGM/C. The majority (96\%) were admitted either to gynaecology or obstetrics divisions with few genito-urinary and psychosexual conditions coded.

Conclusions: FGM/C coding capacities in Swiss university hospitals are low, and some complications of FGM/C are probably not diagnosed. Pregnancy and delivery represent key moments to identify and offer medical care to women and girls who live with $\mathrm{FGM} / \mathrm{C}$.

Trial registration: This cross-sectional study (protocol number 2018-01851) was conducted in 2019, and approved by the Swiss ethics committee.

\section{Plain English Summary}

Female genital mutilation/Cutting (FGM/C) can result in short and long-term complications, which can impact physical, psychological and sexual health. Our objective was to obtain descriptive data about the most frequent health conditions and procedures associated with FGM/C among inpatients with a diagnosis of FGM/C in Swiss university hospitals. We asked the Swiss university hospitals anonymized data of women and girls with a coded FGM/C diagnose who had been admitted between 2016 and 2018. Four of the five Swiss university hospitals provided the primary and secondary diagnoses coded with the International Classification of Diseases (ICD) and the interventions coded in their medical files. Only 207 inpatients had a diagnosis of FGM/C. The majority was admitted either to gynaecology or obstetrics divisions. Some complications of FGM/C are probably not diagnosed. Pregnancy and childbirth represent key moments to care for and counsel a population that might not consult or be identified otherwise.

\section{Keywords}

Female genital mutilation, female genital cutting, female genital mutilation/cutting, international classification of diseases, ICD, coding, Switzerland

\section{Introduction}

Female Genital Mutilation/Cutting (FGM/C) comprises all procedures involving partial or total removal of the external female genitalia without medical indication [1]. The World Health Organization (WHO) defines four main types of FGM/C [Table 1] [2]. 200 million women and girls have undergone the practice in 31 countries according to nationally representative household surveys, without counting female migrants with FGM/C who live high-income countries [3, 4]. According to estimates, almost 600,000 individuals living in the European Union are believed to have been exposed to genital cutting (2016) [5], and in Switzerland, approximately 21,706 women and girls are estimated to have undergone the procedure (2018) [6]. These estimates were obtained by indirect measures: multiplying the number of female migrants from an FGM/C practicing country with the FGM/C prevalence rate from the same country. This method does not account for regional and ethnic variations of the practice within countries, and does not include corrections for any changes in attitudes towards FGM/C, which have been described among migrants [7-11]. The actual prevalence of FGM/C among communities of migrants remains unknown $[12,13]$. Recent studies conducted in the United Kingdom (UK) showed significantly less cases of FGM/C than expected among minors according to prevalence estimates $[14,15]$.

Nevertheless, the total number of women and girls who have undergone FGM/C is expected to grow in high-income countries because of increasing migration from countries where FGM/C prevalence remains high [16]. Although several interventions effectively promote 
the abandonment of $\mathrm{FGM} / \mathrm{C}$, many countries are simultaneously facing population growth, with consequent increase in the absolute number of girls exposed to FGM/C [17].

Table 1

Classification of FGM/C types and subtypes according to $\mathrm{WHO}^{2}$.

\begin{tabular}{|c|c|}
\hline $\begin{array}{l}\text { Type I } \\
\text { Type la }\end{array}$ & $\begin{array}{l}\text { Partial or total removal of the clitoral glans (the external and visible part of the clitoris, which is a sensitive part of } \\
\text { the female genitals, with the function of providing sexual pleasure to the woman), and/or the prepuce/clitoral } \\
\text { hood (the fold of skin surrounding the clitoral glans). }\end{array}$ \\
\hline \multirow[t]{2}{*}{ Type lb } & Removal of the prepuce/clitoral hood only \\
\hline & Removal of the clitoral glans with the prepuce/clitoral hood \\
\hline Type II & Partial or total removal of the clitoral glans and the labia minora, with or without removal of the labia majora. \\
\hline Type lla & Removal of the labia minora only \\
\hline Type llb & Partial or total removal of the clitoris and the labia minora \\
\hline Type Ilc & Partial or total removal of the clitoris, the labia minora and the labia majora \\
\hline $\begin{array}{l}\text { Type III } \\
\text { (Infibulation) }\end{array}$ & $\begin{array}{l}\text { Narrowing of the vaginal opening with the creation of a covering seal. The seal is formed by cutting and } \\
\text { repositioning the labia minora, or labia majora. The covering of the vaginal opening is done with or without } \\
\text { removal of the clitoral prepuce/clitoral hood and glans. }\end{array}$ \\
\hline Type Illa & Removal and apposition of the labia minora \\
\hline Type IIIb & Removal and apposition of the labia majora \\
\hline Type IV & $\begin{array}{l}\text { All other harmful procedures to the female genitalia for non-medical purposes, for example, pricking, piercing, } \\
\text { incising, scraping and cauterization. }\end{array}$ \\
\hline
\end{tabular}

It has been widely studied that FGM/C can result in short and long-term complications, which can impact physical, psychological and sexual health [1]. WHO has released an FGM/C cost calculator, revealing the financial burden generated by health complications of FGM/C to be 1.4 billion USD per year [18]. This estimation refers to women and girls living in countries of high-FGM/C prevalence, and not those living in diaspora countries. Systematic reviews and meta-analyses show that female individuals with FGM/C are at higher risk of dyspareunia, genito-urinary complications, prolonged labour and episiotomies [19-21]. Low quality of the studies included was frequently cited as a limitation and some subjects such as the association of $\mathrm{FGM} / \mathrm{C}$ with caesarean section, infertility and HIV are still a matter of debate [19-21]. Depending on the study design, some of the available data about complications and their clinical management may be subject to self-report and recall bias or inappropriate health management due to lacking training and might therefore be biased, incomplete and/or inaccurate [22]. To our knowledge, no study has yet described FGM/C complications and associated procedures using hospital inpatient data coded with the International Classification of Diseases (ICD).

We sought to describe the most frequent health conditions and procedures associated with FGM/C in inpatient women and girls identified from ICD diagnoses of FGM/C from five Swiss university hospitals.

\section{Materials And Methods}

This cross-sectional study (protocol number 2018-01851) was conducted in 2019, and approved by the Swiss ethics committee. We invited all five Swiss university hospitals (Geneva, Lausanne, Bern, Basel and Zurich) to provide anonymized data for all inpatient adult women and girls (<18 years) with a nationality from any of the $30 \mathrm{FGM} / \mathrm{C}$ practicing countries [3] in addition to all inpatients who had a coded diagnosis of FGM/C between January 1, 2016 and December 31, 2018. We did not include inpatients from the Maldives, where FGM/C has been recently reported [23], because no nationally representative survey was available when the study began.

In Swiss university hospitals, healthcare professionals record the diagnosis responsible for the hospitalization (primary diagnosis); eventual complications that arise during the patient's hospital stay, as well as any additional diseases treated (secondary diagnoses) in the patients' electronic medical charts. Professional coders in Switzerland code this information with the German Modification of the tenth edition of the International Classification of Diseases (ICD-10-GM), and interventions are coded with the Swiss Classification of Surgical Interventions (CHOP) [24]. 
We received the requested data from four university hospitals: Geneva (HUG), Lausanne (CHUV), Bern (Inselspital), and Zurich (USZ). The university hospital of Basel (USB) did not participate due to logistical difficulties in data provision. All data were then merged in a single database using STATA version 15.

The data for all inpatient women and girls from the 30 targeted FGM/C countries and all primary and secondary diagnoses of FGM/C coded between January 1, 2016 and December 31, 2018 was anonymized. The university hospital of Bern did not provide data on the interventions performed. Lausanne and Zürich provided CHOP codes of the interventions performed, and Geneva provided the name of the CHOP interventions. We analyzed all diagnoses and interventions in patients' records with a coded primary or secondary diagnosis of FGM/C. We provided descriptive statistics with mean, \pm standard deviation, and median for continuous variables, numbers by categorical variables. We compared all diagnoses from our sample with the FGM/C ICD "tip-sheet" for FGM/C associated health conditions (full methods available in another manuscript) [25]. We focused our analysis on the gynaecology and obstetrics divisions, where most of the inpatients with an FGM/C code were admitted.

The Swiss Federal Office of Public Health, the Swiss Network against Female Circumcision, and Caritas Switzerland funded the study. They had no role in study design, data collection and analysis, decision to publish, or preparation of the manuscript.

\section{Results}

In four of the five Swiss university hospitals, 207 inpatients received a primary $(n=22,10.6 \%)$ or a secondary $(n=185)$ diagnosis of FGM/C during the study period [Table 2]. Of these 207 women and girls, 199 (96\%, 89.4\%) were admitted either to gynaecology or obstetrics divisions. The remaining women and girls were admitted to other departments (surgery, internal medicine, emergency, and paediatrics). 
Table 2

Description of inpatients with a FGM/C ( $\mathrm{n}=207)$ as primary or secondary diagnosis between 2016 and 2018 followed in one of four Swiss university hospitals (Geneva, Lausanne, Bern and Zurich).

\begin{tabular}{|c|c|c|c|}
\hline Variables & $\begin{array}{l}2016 \\
(n=42)\end{array}$ & $\begin{array}{l}2017 \\
(n=69)\end{array}$ & $\begin{array}{l}2018 \\
(n=96)\end{array}$ \\
\hline \multicolumn{4}{|l|}{ Center, n (\%) } \\
\hline Geneva & $20(47.6)$ & $24(34.8)$ & $67(69.8)$ \\
\hline Lausanne & $13(31.0)$ & $10(14.5)$ & $19(19.8)$ \\
\hline Bern & $3(7.1)$ & $23(33.3)$ & $6(6.3)$ \\
\hline Zurich & $6(14.3)$ & $12(17.4)$ & $4(4.2)$ \\
\hline \multicolumn{4}{|l|}{ Country of origin, n (\%) } \\
\hline Benin & $0(0)$ & $0(0)$ & $1(1.0)$ \\
\hline Burkina Faso & $1(2.4)$ & $2(2.9)$ & $0(0)$ \\
\hline Cameroon & $1(2.4)$ & $0(0)$ & $0(0)$ \\
\hline Côte d'Ivoire & $1(2.4)$ & $1(1.5)$ & $1(1.0)$ \\
\hline Egypt & $0(0)$ & $0(0)$ & $5(5.2)$ \\
\hline Eritrea & $12(28.6)$ & $37(53.6)$ & $36(37.5)$ \\
\hline Ethiopia & $2(4.8)$ & $3(4.4)$ & $2(2.1)$ \\
\hline Guinea & $0(0)$ & $0(0)$ & $6(6.2)$ \\
\hline Guinea-Bissau & $0(0)$ & $0(0)$ & $2(2.1)$ \\
\hline Mali & $0(0)$ & $0(0)$ & $1(1.0)$ \\
\hline Mauritania & $0(0)$ & $0(0)$ & $1(1.0)$ \\
\hline Nigeria & $1(2.4)$ & $1(1.5)$ & $3(3.1)$ \\
\hline Senegal & $0(0)$ & $0(0)$ & $3(3.1)$ \\
\hline Somalia & $14(33.3)$ & $18(26.1)$ & $22(22.9)$ \\
\hline Sudan and South Sudan & $1(2.4)$ & $1(1.5)$ & $3(3.1)$ \\
\hline Unknown or other & $9(21.4)$ & $6(8.7)$ & $10(10.4)$ \\
\hline \multicolumn{4}{|l|}{ Service, n (\%) } \\
\hline Gynecology & $13(31.0)$ & $12(17.4)$ & $9(9.4)$ \\
\hline Gynecology or Obstetrics ${ }^{a}$ & $1(2.4)$ & $23(33.3)$ & $6(6.3)$ \\
\hline Obstetrics & $23(54.8)$ & $33(47.8)$ & $79(82.3)$ \\
\hline Others & $5(11.9)$ & $1(1.5)$ & $2(2.1)$ \\
\hline Mean age at first visit $( \pm S D$, median) & $30.7( \pm 12.0,27)$ & $27.7( \pm 6.1,27.4)$ & $29.8( \pm 6.7,30)$ \\
\hline
\end{tabular}

a Data obtained from Bern did not specify whether patients were admitted in gynecology or obstetrics. 


\begin{tabular}{|llll|}
\hline Variables & $\begin{array}{l}\mathbf{2 0 1 6} \\
(\mathbf{n = 4 2})\end{array}$ & $\begin{array}{l}\mathbf{2 0 1 7} \\
(\mathbf{n = 6 9 )}\end{array}$ & $\begin{array}{l}\mathbf{2 0 1 8} \\
(\mathbf{n = 9 6 )}\end{array}$ \\
\hline FGM/C type, $\mathrm{n}(\%)$ & $3(7.1)$ & $13(18.8)$ & $10(10.4)$ \\
Type I & & & \\
& & & \\
& $8(19.1)$ & $16(23.2)$ & $33(34.4)$ \\
Type II & $21(50.0)$ & $33(47.8)$ & $39(40.6)$ \\
Type III & $0(0)$ & $1(1.5)$ & $2(2.1)$ \\
Type IV & $10(23.8)$ & $6(8.7)$ & $12(12.5)$ \\
Unspecified or other & & & \\
\hline a Data obtained from Bern did not specify whether patients were admitted in gynecology or obstetrics. & \\
\hline
\end{tabular}

The primary diagnoses of women with a secondary diagnosis of FGM/C $(n=185)$ spanned 11 chapters of the ICD-10 [Table 3]. 156 inpatients had a primary diagnosis related to pregnancy and childbirth. The most frequent diagnoses were perineal laceration during delivery $(n=29,18.6 \%)$, labour and delivery complicated by fetal heart rate anomaly $(n=16,10.3 \%)$, prolonged second stage of labour $(n=13,8.3 \%)$ and premature rupture of membranes $(n=13,8.3 \%)$. Nine patients were admitted for some type of anaemia: anaemia complicating pregnancy, childbirth and the puerperium $(n=5)$, iron deficiency anaemia $(n=3)$, and post-haemorrhagic anaemia $(n=1)$. Primary diagnoses of genitourinary diseases included vulvar cysts $(n=4)$, and infectious diseases such as abscess of vulva $(n=2)$, chronic salpingitis and oophoritis $(n=1)$ and pyonephrosis $(n=1)$.

The mean number of secondary diagnoses coded among women with a primary or secondary diagnosis of FGM/C was 2.59 (median 2 , range $0-15)$, spanning 16 chapters of the ICD-10 [Table 4]. There were 281 secondary diagnoses related to pregnancy and childbirth, including 114 codes describing duration of pregnancy $(009.1-009.7,048)$. Other frequent codes were perineal laceration during delivery $(n=21)$, prolonged second stage of labour $(n=8)$, and anaemia complicating pregnancy, childbirth and the puerperium $(n=24)$. 
Variables

ICD-10 chapter ICD-10 diagnoses

and codes

Neoplasms

C77.4, C90.00 Malignant neoplasms

D25.9

Leiomyoma of uterus, unspecified

Diseases of the blood and blood-forming organs and certain disorders involving the immune mechanism

D50.8, D50.9 Iron deficiency anemias

3

D62

Acute posthemorrhagic anemia

Endocrine, nutritional and metabolic diseases

E55.9 Vitamin D deficiency, unspecified

Diseases of the circulatory system

I05.0 Rheumatic mitral stenosis

1

\section{Diseases of the skin and subcutaneous tissue}

L02.2 Cutaneous abscess, furuncle and carbuncle of trunk

1

\section{Diseases of the genitourinary system}

N13.1 Hydronephrosis with ureteral stricture, not elsewhere classified

N13.6 Pyonephrosis

1

N39.3

Stress incontinence

1

N70.1

Chronic salpingitis and oophoritis

N76.4

Abscess of vulva

N84.0

Polyp of corpus uteri

1

N90.7

Vulvar cyst

Pregnancy, childbirth and the puerperium

000.1

Tubal pregnancy

1

002.1

Missed abortion

1

009.6

"Duration of pregnancy 37 to 41 completed weeks, 253 to 287 completed days"

4

009.7

"Duration of pregnancy More than 41 completed weeks More than 287 completed days"

012.1 Gestational proteinuria

014.0, 014.1, Pre-eclampsia

014.9

024.0

Pre-existing type 1 diabetes mellitus, in pregnancy, childbirth and the puerperium

024.4 Gestational diabetes mellitus

030.0 Twin pregnancy

032.1 Maternal care for breech presentation 


\section{Variables}

034.2

034.30

034.7

036.5

036.6

041.0

041.1

042.0, 042.11, Premature rupture of membranes, onset of labor within 24 hours of rupture

042.12

043.21

044.11

048

060.1

061.0

062.8

063.0

063.1

064.8

065.4

066.2

066.5

068.0

068.2

070.0

070.1

070.2

070.3

070.9

071.1

072.0, 072.1

075.6

075.7

080

098.8

099.0

099.1

Maternal care due to uterine scar from previous surgery

Maternal care for cervical incompetence, unspecified trimester

Maternal care for abnormality of vulva and perineum

Maternal care for known or suspected poor fetal growth

Maternal care for excessive fetal growth

Oligohydramnios

Infection of amniotic sac and membranes

Placenta accreta

Complete placenta previa with hemorrhage, first trimester

Post-term pregnancy

Preterm labor with preterm delivery

Failed medical induction of labor

Other abnormalities of forces of labor

Prolonged first stage (of labor)

Prolonged second stage (of labor)

Obstructed labor due to other malposition and malpresentation

Obstructed labor due to fetopelvic disproportion, unspecified

Obstructed labor due to unusually large fetus

Attempted application of vacuum extractor and forceps

Labour and delivery complicated by fetal heart rate anomaly

First degree perineal laceration during delivery

Second degree perineal laceration during delivery

Third degree perineal laceration during delivery

Fourth degree perineal laceration during delivery

Perineal laceration during delivery, unspecified

Rupture of uterus during labour

Third-stage haemorrhage

Delayed delivery after spontaneous or unspecified rupture of membranes

Vaginal delivery following previous caesarean section

Single spontaneous delivery

Anaemia complicating pregnancy, childbirth and the puerperium
3

1

1

4

2

2

1

13

1

2

4

2

2

4

13

1

1

1

1

Labour and delivery complicated by fetal heart rate anomaly with meconium in amniotic fluid

3

2

1

3

1

2

3

Other maternal infectious and parasitic diseases complicating pregnancy, childbirth and the puerperium $\quad 1$

Other diseases of the blood and blood-forming organs and certain disorders involving the immune mechanism complicating pregnancy, childbirth and the puerperium 


\begin{tabular}{|c|c|c|}
\hline \multicolumn{2}{|c|}{ Variables } & \multirow{2}{*}{$\begin{array}{l}\mathbf{N} \\
1\end{array}$} \\
\hline 099.2 & Endocrine, nutritional and metabolic diseases complicating pregnancy, childbirth and the puerperium & \\
\hline 099.8 & Other specified diseases and conditions complicating pregnancy, childbirth and the puerperium & 4 \\
\hline \multicolumn{2}{|c|}{ Congenital malformations, deformations and chromosomal abnormalities } & 1 \\
\hline Q50.5 & Embryonic cyst of broad ligament & 1 \\
\hline \multicolumn{2}{|c|}{ Symptoms, signs and abnormal clinical and laboratory findings, not elsewhere classified } & 1 \\
\hline R74.0 & Elevation of levels of transaminase and lactic acid dehydrogenase [LDH] & 1 \\
\hline \multicolumn{2}{|c|}{ Injury, poisoning and certain other consequences of external causes } & 1 \\
\hline S72.3 & Fracture of shaft of femur & 1 \\
\hline \multicolumn{2}{|c|}{ Factors influencing health status and contact with health services } & 18 \\
\hline Z37.0 & Single live birth & 4 \\
\hline Z65 & Problems related to other psychosocial circumstances & 1 \\
\hline Z91.70 & Personal history of female genital mutilation, type unspecified & 1 \\
\hline Z91.71 & Personal history of female genital mutilation, type 1 & 1 \\
\hline Z91.72 & Personal history of female genital mutilation, type 2 & 2 \\
\hline Z91.73 & Personal history of female genital mutilation, type 3 & 9 \\
\hline
\end{tabular}


ICD-10 chapter and ICD-10 diagnoses

codes

Certain infectious and parasitic diseases

A39.0

Meningococcal meningitis

2

A60.9

Anogenital herpesviral infection, unspecified

1

B18.1

Chronic viral hepatitis B without Delta virus

B65.0

Schistosomiasis due to Schistosoma haematobium [urinary schistosomiasis]

B68.1

Taenia saginata taeniasis

B95.1

Streptococcus, group B, as the cause of diseases classified elsewhere

B95.91

Other specified gram-positive anaerobic, non-spore forming pathogens causing diseases, classified 1 elsewhere

B96.2

Escherichia coli [E. coli ] as the cause of diseases classified elsewhere

B98.0

Helicobacter pylori [H. pylori] as the cause of diseases classified in other chapters

1

Diseases of the blood and blood-forming organs and certain disorders involving the immune mechanism

D50.0

Iron deficiency anemia secondary to blood loss (chronic)

D50.8, D50.9

Iron deficiency anemias

D52.9

Folate deficiency anemia, unspecified

1

D57.1

Sickle-cell disease without crisis

D62

Acute posthemorrhagic anemia

D64.8, D64.9

Anemia, other or unspecified

6

D68.4, D68.9

Coagulation defect

2

D90

Immune compromise after radiation, chemotherapy and other immunosuppressive measures

1

Endocrine, nutritional and metabolic diseases

E03.8, E03.9

Hypothyroidism

6

E11.60

Type 2 diabetes mellitus with other specified complications

E44.0

Moderate protein-calorie malnutrition

E53.8

Deficiency of other specified B group vitamins

E55.9

Vitamin $D$ deficiency, unspecified

2

E66.00, E66.91

Obesity

E83.38

Other disorders of phosphorus metabolism and phosphatase

1

E87.6 Hypokalemia

Mental, Behavioral and Neurodevelopmental disorders

F32.8

Other depressive episodes

F43.1

Post-traumatic stress disorder (PTSD) 
Variables

Diseases of the nervous system

G01

Meningitis in bacterial diseases classified elsewhere

G57.2

Lesion of femoral nerve

1

Diseases of the circulatory system

\section{5}

105.0, 107.1

Heart valve diseases

2

110.90

Essential hypertension, unspecified: No indication of a hypertensive crisis

1

148.9 Unspecified atrial fibrillation and atrial flutter

195.8

Other hypotension

Diseases of the respiratory system

J90

Pleural effusion, not elsewhere classified

Diseases of the digestive system

K21.9

Gastro-esophageal reflux disease without esophagitis

1

K59.0

Constipation

1

$\mathrm{K} 64.3$

Fourth degree hemorrhoids

1

K66.1

Hemoperitoneum

K66.8

Other specified disorders of peritoneum

Diseases of the skin and subcutaneous tissue

L20.8

Dermatitis

2

Diseases of the musculoskeletal system and connective tissue

M54.2

Cervicalgia

Diseases of the genitourinary system

N06.8

Isolated proteinuria with other morphologic lesion

N13.6

Pyonephrosis

N18.9

Chronic kidney disease, unspecified

1

N39.0

Urinary tract infection, site not specified

N73.6

Female pelvic peritoneal adhesions

1

N80.3

Endometriosis of pelvic peritoneum

1

N83.8

Other noninflammatory disorders of ovary, fallopian tube and broad ligament

1

N87.0

Mild cervical dysplasia

1

N90.7

Vulvar cyst

1

N90.8

Other specified noninflammatory disorders of vulva and perineum

N90.80

Female genital mutilation, type unspecified

N90.81

Female Genital Mutilation, Type 1

N90.82

Female Genital Mutilation, Type 2

3

N90.83

Female Genital Mutilation, Type 3 


\begin{tabular}{|c|c|c|}
\hline \multicolumn{2}{|l|}{ Variables } & \multirow{2}{*}{$\begin{array}{l}\mathbf{N} \\
6\end{array}$} \\
\hline N90.88 & Other specified non-inflammatory diseases of the vulva and perineum (FGM, Unspecified or other) & \\
\hline N92.0 & Excessive and frequent menstruation with regular cycle & 2 \\
\hline N94.1 & Dyspareunia & 2 \\
\hline N94.4 & Primary dysmenorrhea & 1 \\
\hline N97.1 & Female infertility of tubal origin & 1 \\
\hline \multicolumn{2}{|c|}{ Pregnancy, childbirth and the puerperium } & 281 \\
\hline 008.1 & Delayed or excessive haemorrhage following abortion and ectopic and molar pregnancy & 1 \\
\hline 009.1 & "Duration of pregnancy 5 to 13 completed weeks, 35 to 91 completed days" & 2 \\
\hline 009.2 & "Duration of pregnancy 14 to 19 completed weeks, 92 to 133 completed days" & 4 \\
\hline 009.3 & "Duration of pregnancy 20 to 25 completed weeks, 134 to 175 completed days" & 2 \\
\hline 009.4 & "Duration of pregnancy 26 to 33 completed weeks, 176 to 231 completed days" & 6 \\
\hline 009.5 & "Duration of pregnancy 34 to 36 completed weeks, 232 to 252 completed days" & 3 \\
\hline 009.6 & "Duration of pregnancy 37 to 41 completed weeks, 253 to 287 completed days" & 72 \\
\hline 009.7 & "Duration of pregnancy more than 41 completed weeks, more than 287 completed days" & 15 \\
\hline 013 & Gestational [pregnancy-induced] hypertension without significant proteinuria & 1 \\
\hline 014.9 & Unspecified pre-eclampsia & 1 \\
\hline 016 & Unspecified maternal hypertension & 2 \\
\hline $024.1,024.3$ & Pre-existing diabetes mellitus, in pregnancy, childbirth and the puerperium & 4 \\
\hline 024.4 & Gestational diabetes mellitus & 6 \\
\hline 032.2 & Maternal care for transverse and oblique lie & 2 \\
\hline 033.4 & Maternal care for disproportion of mixed maternal and fetal origin & 3 \\
\hline 034.2 & Maternal care due to uterine scar from previous surgery & 4 \\
\hline 034.6 & Maternal care for abnormality of vagina & 3 \\
\hline 034.7 & Maternal care for abnormality of vulva and perineum & 3 \\
\hline 036.0 & Maternal care for rhesus isoimmunization & 2 \\
\hline 036.5 & Maternal care for known or suspected poor fetal growth & 1 \\
\hline 036.6 & Maternal care for excessive fetal growth & 1 \\
\hline 041.0 & Oligohydramnios & 2 \\
\hline $042.0,042.11$ & Premature rupture of membranes, onset of labor within 24 hours of rupture & 3 \\
\hline 043.20 & Placenta accreta & 2 \\
\hline 044.11 & Complete placenta previa with hemorrhage, first trimester & 1 \\
\hline 045.9 & Premature detachment of the placenta, unspecified & 1 \\
\hline 048 & Post-term pregnancy & 10 \\
\hline 060.1 & Preterm labor with preterm delivery & 1 \\
\hline 060.3 & Preterm delivery without spontaneous labour & 5 \\
\hline
\end{tabular}




\begin{tabular}{|c|c|c|}
\hline Variables & & $\mathbf{N}$ \\
\hline 061.0 & Failed medical induction of labor & 2 \\
\hline 062.1 & Secondary uterine inertia & 3 \\
\hline 063.0 & Prolonged first stage (of labor) & 2 \\
\hline 063.1 & Prolonged second stage (of labor) & 8 \\
\hline 064.1 & Obstructed labour due to breech presentation & 1 \\
\hline 064.8 & Obstructed labor due to other malposition and malpresentation & 1 \\
\hline 066.8 & Other specified obstructed labor & 2 \\
\hline 068.0 & Labour and delivery complicated by fetal heart rate anomaly & 2 \\
\hline 069.8 & Labour and delivery complicated by other cord complications & 1 \\
\hline 070.0 & First degree perineal laceration during delivery & 14 \\
\hline 070.1 & Second degree perineal laceration during delivery & 7 \\
\hline 071.3 & Obstetric laceration of cervix & 1 \\
\hline 071.8 & Other specified obstetric trauma & 2 \\
\hline $072.0,072.1$ & Third-stage haemorrhage & 9 \\
\hline 072.3 & Postpartum coagulation defects & 1 \\
\hline 073.0 & Retained placenta without haemorrhage & 1 \\
\hline 073.1 & Retained portions of placenta and membranes, without haemorrhage & 1 \\
\hline 075.7 & Vaginal delivery following previous caesarean section & 3 \\
\hline 085 & Puerperal sepsis & 1 \\
\hline 086.2 & Urinary tract infection following delivery & 1 \\
\hline 087.2 & Haemorrhoids in the puerperium & 1 \\
\hline 090.2 & Haematoma of obstetric wound & 1 \\
\hline 098.3 & $\begin{array}{l}\text { Other infections with a predominantly sexual mode of transmission complicating pregnancy, } \\
\text { childbirth and the puerperium }\end{array}$ & 1 \\
\hline 098.4 & Viral hepatitis complicating pregnancy, childbirth and the puerperium & 1 \\
\hline 098.8, 098.9 & Maternal infectious and parasitic diseases complicating pregnancy, childbirth and the puerperium & 2 \\
\hline 099.0 & Anaemia complicating pregnancy, childbirth and the puerperium & 24 \\
\hline 099.2 & $\begin{array}{l}\text { Endocrine, nutritional and metabolic diseases complicating pregnancy, childbirth and the } \\
\text { puerperium }\end{array}$ & 7 \\
\hline 099.3 & $\begin{array}{l}\text { Mental disorders and diseases of the nervous system complicating pregnancy, childbirth and the } \\
\text { puerperium }\end{array}$ & 2 \\
\hline 099.6 & Diseases of the digestive system complicating pregnancy, childbirth and the puerperium & 2 \\
\hline 099.7 & $\begin{array}{l}\text { Diseases of the skin and subcutaneous tissue complicating pregnancy, childbirth and the } \\
\text { puerperium }\end{array}$ & 2 \\
\hline 099.8 & Other specified diseases and conditions complicating pregnancy, childbirth and the puerperium & 12 \\
\hline \multicolumn{2}{|c|}{ Symptoms, signs and abnormal clinical and laboratory findings, not elsewhere classified } & 3 \\
\hline R30.0 & Dysuria & 1 \\
\hline
\end{tabular}




\begin{tabular}{|c|c|c|}
\hline \multicolumn{2}{|l|}{ Variables } & \multirow{2}{*}{$\begin{array}{l}\mathbf{N} \\
1\end{array}$} \\
\hline R74.8 & Abnormal levels of other serum enzymes & \\
\hline R82.3 & Abnormal findings on cytological and histological examination of urine & 1 \\
\hline \multicolumn{2}{|c|}{ Definition of HIV infection stages } & 2 \\
\hline U60.9, U61.9 & HIV classification & 2 \\
\hline \multicolumn{2}{|c|}{ External causes of morbidity } & 2 \\
\hline Y57.9 & Drug or medicament, unspecified & 1 \\
\hline Y84.9 & Medical procedure, unspecified & 1 \\
\hline \multicolumn{2}{|c|}{ Factors influencing health status and contact with health services } & 290 \\
\hline $\mathrm{Z} 21$ & Asymptomatic human immunodeficiency virus (HIV) infection status & 1 \\
\hline Z22.3, Z22.8 & Carrier of other infectious diseases & 17 \\
\hline Z25.8, Z27.3, Z27.4 & Need for immunization against specified viral diseases & 8 \\
\hline Z30.4 & Surveillance of contraceptive drugs & 1 \\
\hline Z34 & Supervision of normal pregnancy & 3 \\
\hline Z35.2, Z35.4, Z35.8 & Supervision of high-risk pregnancy & 4 \\
\hline Z37.0 & Single live birth & 91 \\
\hline Z37.2 & Twins, both liveborn & 1 \\
\hline Z59 & Problems related to housing and economic circumstances & 1 \\
\hline Z64.8, Z65 & Problems related to certain psychosocial circumstances & 4 \\
\hline Z86.1 & Personal history of infectious and parasitic diseases & 1 \\
\hline Z86.7 & Personal history of diseases of the circulatory system & 2 \\
\hline Z87.8 & Personal history of other specified conditions & 1 \\
\hline Z91.70 & Personal history of female genital mutilation, type unspecified & 17 \\
\hline Z91.71 & Personal history of female genital mutilation, type 1 & 22 \\
\hline Z91.72 & Personal history of female genital mutilation, type 2 & 47 \\
\hline Z91.73 & Personal history of female genital mutilation, type 3 & 63 \\
\hline Z91.74 & Personal history of female genital mutilation, type 4 & 3 \\
\hline Z92.1 & Personal history of long-term (current) use of anticoagulants & 2 \\
\hline Z94.0 & Kidney transplant status & 1 \\
\hline
\end{tabular}

Among diseases of the genitourinary system, coded diagnoses featured vulvar cyst $(n=1)$, urinary tract infection $(n=1)$ and mild cervical dysplasia $(n=1)$. Other secondary diagnoses related to infections were Streptococcus group B $(n=17)$, possibly describing a carrier-state in pregnant women, and carrier of other specified bacterial or infectious diseases $(n=17)$, and asymptomatic HIV status $(n=1)$. Eight women required immunization against viral diseases such as measles, diphtheria, and other viral diseases.

Mental disorders and sexual health conditions were rarely coded as either primary or secondary conditions. "Problems related to psychosocial and/or economic circumstances" appeared five times as secondary diagnosis, and once as a primary diagnosis for a minor inpatient that was admitted in paediatrics. Out of the other four minors with a code of FGM/C $(n=5)$, another was admitted in paediatrics to undergo surgery for mitral valve stenosis, and the remaining two were admitted in gynaecology for surgical treatment of a vulvar cyst. The only minor inpatient with a primary diagnosis of FGM/C underwent defibulation and had secondary codes related to pregnancy. 
In total, there were 62 primary and secondary diagnoses of anaemia in 36 patients admitted in gynaecology or obstetrics. Among them, six had third-stage haemorrhage, six a first- or second-degree perineal tear, and nine underwent caesarean section. 27 of 135 patients admitted in obstetrics (19\%), had a primary or secondary diagnosis of anemia complicating pregnancy and childbirth.

Several coded diagnoses in our sample might be possible long-term complications of FGM/C found in the FGM/C "tip-sheet" (25) [Table 5]. The most frequently coded diagnoses (primary and secondary combined) were: perineal laceration during delivery ( $n=50)$, prolonged second stage of labour $(n=21)$, postpartum haemorrhage $(n=12)$, and vulvar cysts $(n=5)$. 
Specific codes for long-term complications to FGM/C when FGM/C was coded as primary or secondary diagnosis.

Variables

.

Primary diagnosis of
FGM/C $(n=22)$

Secondary diagnosis

of FGM/C

$(n=185)$
ICD-10

code

B20-24 0

0

Human immunodeficiency virus (HIV) disease

B20-24 0

Mental, Behavioral and Neurodevelopmental disorders

Recurrent depressive disorder

F32-33 0

1

Generalized anxiety disorder

F41.1 0

F43.1 0

F52 0

1

Sexual dysfunction, not due to an organic condition

Diseases of the genitourinary system

Cystitis

Urinary tract infection, site not specified

Other inflammation of vagina and vulva

Dysplasia of cervix uteri

Other specified non-inflammatory disorders of vagina

Vulvar cyst

Non-inflammatory disorder of vulva and perineum, unspecified

Dyspareunia

Dysmenorrhea, unspecified

Other specified conditions associated with female genital organs and menstrual cycle

\section{Pregnancy, childbirth and the puerperium}

Prolonged second stage of labour

First degree perineal laceration during delivery

Second degree perineal laceration during delivery

Third degree perineal laceration during delivery

Fourth degree perineal laceration during delivery

Perineal laceration during delivery, unspecified

Obstetric high vaginal laceration

Other specified obstetric trauma

Obstetric trauma, unspecified

Postpartum haemorrhage

Low forceps delivery

Other and unspecified forceps delivery

$063.1 \quad 13 \quad 8$

$\begin{array}{lll}070.0 & 13 & 14\end{array}$

$\begin{array}{lll}070.1 & 11 & 7\end{array}$

$\begin{array}{lll}070.2 & 1 & 0\end{array}$

070.320

070.9220

071.40

$071.8 \quad 0 \quad 2$

071.900

072.0, 3

072.1

081.000

081.300




\begin{tabular}{|llll|}
\hline Variables & & $\begin{array}{l}\text { Primary diagnosis of } \\
\text { FGM/C (n=22) }\end{array}$ & $\begin{array}{l}\text { Secondary diagnosis } \\
\text { of FGM/C } \\
(\mathbf{n}=185)\end{array}$ \\
\hline Vacuum extractor delivery & 081.4 & 0 & 0 \\
\hline Single delivery by caesarean section & 082 & 0 & 0 \\
\hline Disruption of perineal obstetric wound & 090.1 & 0 & 0 \\
\hline Certain conditions originating in the perinatal period & & & 0 \\
\hline Birth trauma & $\mathrm{P} 10-15$ & 0 & 0 \\
\hline
\end{tabular}

Medical or surgical interventions were carried out in 110 (56,5\%) patients with FGM/C: 47 interventions in Geneva, 42 in Lausanne and 22 in Zürich [Table 6]. The most frequent obstetrical intervention was caesarean sections ( $\mathrm{n}=29) .14$ patients had an episiotomy and 15 required unspecified manual assistance during delivery. The most frequent intervention aimed at treating complications of FGM/C was surgery of the clitoris ( $n=11$ ). In Geneva, four inpatients underwent defibulation. 
Main intervention reported among patients with FGM/C according to hospital.

\begin{tabular}{|c|c|c|c|}
\hline Variables & $\begin{array}{l}\text { Geneva } \\
(n=111)\end{array}$ & $\begin{array}{l}\text { Lausanne } \\
(n=42)\end{array}$ & $\begin{array}{l}\text { Zürich } \\
(n=22)\end{array}$ \\
\hline \multicolumn{4}{|l|}{ Obstetrical interventions } \\
\hline Cerclage of the cervix & 1 & 0 & 0 \\
\hline Pharmaceutical induction of labour & 0 & 1 & 0 \\
\hline \multicolumn{4}{|l|}{ Manual assistance during delivery: } \\
\hline - with episiotomy and instrumentation & 0 & 1 & 2 \\
\hline - with episiotomy only & 0 & 5 & 6 \\
\hline - unspecified & 0 & 13 & 2 \\
\hline Caesarean section & 20 & 8 & 1 \\
\hline Perineal tear repair & 2 & 6 & 0 \\
\hline Curettage for retained placenta & 1 & 1 & 0 \\
\hline \multicolumn{4}{|l|}{ Gynaecological interventions } \\
\hline Ovarian cyst excision & 1 & 0 & 0 \\
\hline Myomectomy & 1 & 0 & 0 \\
\hline Salpingectomy & 1 & 0 & 1 \\
\hline \multicolumn{4}{|l|}{ Interventions related to FGM/C } \\
\hline Clitoral surgery & 8 & 3 & 0 \\
\hline Vulvar cyst excision & 2 & 0 & 0 \\
\hline Vulvar abscess incision and drainage & 1 & 0 & 0 \\
\hline Defibulation & 4 & 0 & 0 \\
\hline \multicolumn{4}{|l|}{ Interventions possibly related to FGM/C } \\
\hline \multirow[t]{5}{*}{ Hymenectomy ${ }^{a}$} & 0 & 0 & 1 \\
\hline & 0 & 0 & 5 \\
\hline & 0 & 0 & 4 \\
\hline & 0 & 1 & 0 \\
\hline & 0 & 1 & 0 \\
\hline Repair of vulva and perineum ${ }^{a}$ & 0 & 1 & 0 \\
\hline Incision of vulva and perineum ${ }^{b}$ & 1 & 0 & 0 \\
\hline Other interventions & 1 & 0 & 0 \\
\hline Femoral fracture repair & 1 & 0 & 0 \\
\hline Hematopoietic stem cell transplant & 0 & 1 & 0 \\
\hline Lymph node biopsy & 1 & 0 & 0 \\
\hline \multicolumn{4}{|l|}{ a Patients with FGM/C type III } \\
\hline${ }^{b}$ Three patients with FGM/C type III, o & nt with & C type II & \\
\hline
\end{tabular}




\begin{tabular}{|c|c|c|c|}
\hline Variables & $\begin{array}{l}\text { Geneva } \\
(n=111)\end{array}$ & $\begin{array}{l}\text { Lausanne } \\
(n=42)\end{array}$ & $\begin{array}{l}\text { Zürich } \\
(n=22)\end{array}$ \\
\hline \multicolumn{4}{|l|}{ Mitral valvuloplasty } \\
\hline \multicolumn{4}{|l|}{ Retrograde ureteropyelography } \\
\hline \multicolumn{4}{|l|}{ Ureteral pigtail placement } \\
\hline \multicolumn{4}{|l|}{$\begin{array}{l}\text { Transvaginal suspension for urinary } \\
\text { incontinence }\end{array}$} \\
\hline \multicolumn{4}{|l|}{ Trunk abscess incision and drainage } \\
\hline \multicolumn{4}{|l|}{ 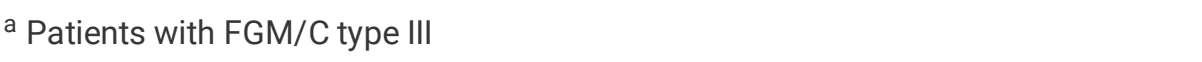 } \\
\hline b Three patients with FGM/C type III, C & tt with $\mathrm{FC}$ & C type II & \\
\hline
\end{tabular}

\section{Discussion}

\section{Main Findings}

In four Swiss university hospitals, 207 inpatients had a primary $(n=22,10.6 \%)$ or secondary $(n=185,89.4 \%)$ diagnosis of FGM/C coded at admission between 2016 and 2018 [26]. As discussed in another paper, this was much less than expected when compared with the number of inpatients who could have undergone FGM/C based on their nationality and indirect estimates $(n=4947)$ [26]. Either fewer women than expected have undergone FGM/C, or healthcare professionals did not identify and/or record the practice, resulting in suboptimal coding. Nearly all patients with a coded diagnosis of FGM/C were admitted to an obstetrics and/or gynaecology division, and most of their primary and secondary diagnoses were related to pregnancy and delivery.

\section{Limitations and Strengths}

Limitations included the absence of participation from Basel, of interventions' data from Bern, and the exclusion of non-university hospitals, where most deliveries of women in the cantons of Bern and Zürich occur [Tables 7 and 8] [27-34]. Future studies could assess the prevalence of FGM/C and associated health outcomes in all cantons and hospitals, and study regional variations, such as in areas near asylum centres. We did not study outpatients' data, which would provide information on the health conditions treated and interventions performed (e.g. defibulation) in ambulatory care. The application of our method is mostly limited by undercoding of FGM/C, which most likely results from insufficient training about FGM/C [26]. Future prospective and case-control studies could assess the coding of FGM/C associated health outcomes according to training resources and possibility of referral to a specialised clinic. 
Table 7

Number of deliveries between 2016 and 2018

according to center ${ }^{53-59}$

\begin{tabular}{|llll|}
\hline & 2016 & 2017 & 2018 \\
\hline Geneva (HUG) & 4101 & 4182 & 4213 \\
\hline Vaud (CHUV) & 3230 & 3227 & 3375 \\
\hline Bern (Inselspital) & 1810 & 1827 & 2004 \\
\hline Zürich & 2960 & 2971 & 2969 \\
(USZ) & & & \\
\hline
\end{tabular}

Table 8

Living births according to canton and nationality category of the mother ${ }^{60}$.

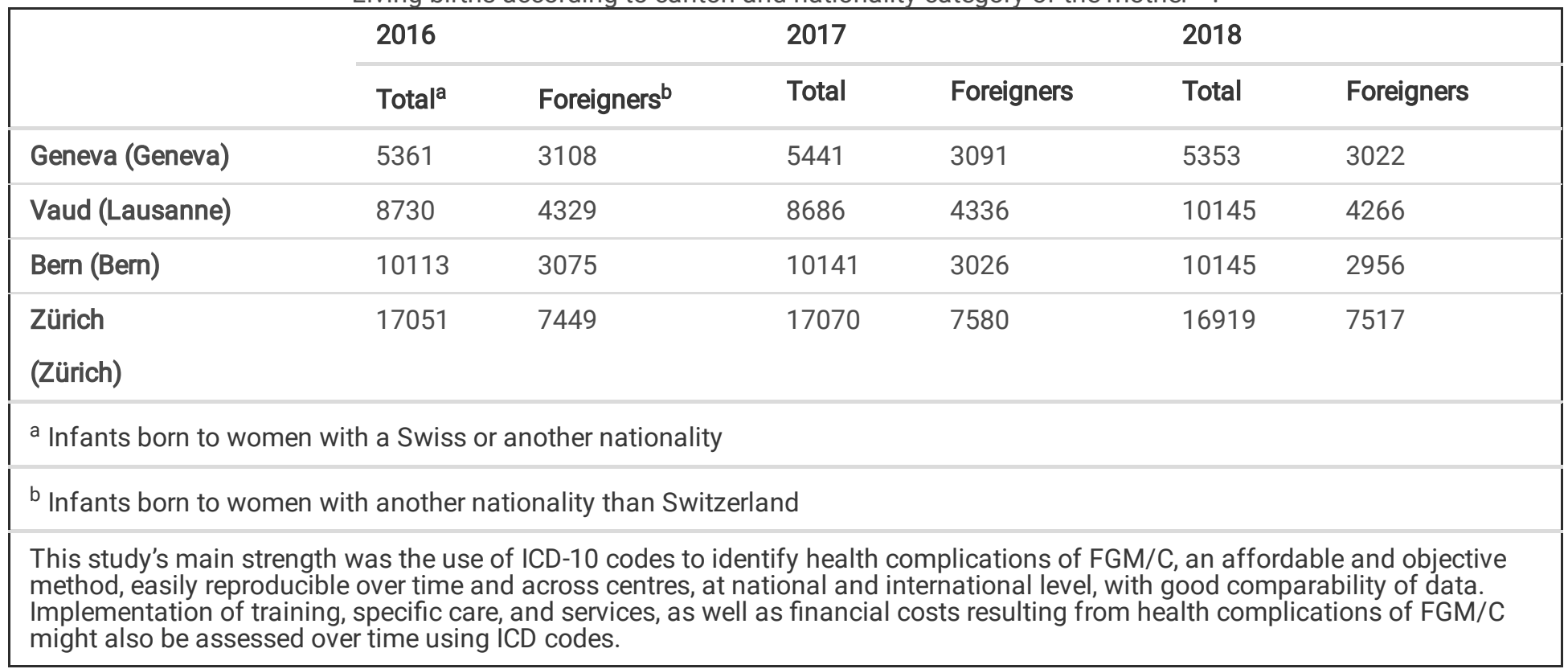

\section{Interpretation}

Women with FGM/C might consult, be admitted or referred more frequently when pregnant, resulting in better FGM/C coding in obstetrics divisions. Furthermore, Swiss basic health insurance covers most costs related to pregnancy, facilitating access to healthcare [35]. Obstetricians and gynaecologists routinely perform genital examinations and are more likely trained to diagnose $\mathrm{FGM} / \mathrm{C}$ [26]. FGM/C is also more likely to be recorded in obstetrics charts, because it can influence childbirth [1]. For instance, UK's report on FGM/C prevalence in the National Health System (NHS) showed that 1630 women and girls had a consultation where FGM/C was recorded between October and December 2020, with $74.9 \%$ of attendances in midwifery or obstetrical units [36]. Antenatal consultations provide major opportunities to identify and care for individuals with $\mathrm{FGM} / \mathrm{C}$ who might not seek or receive medical attention otherwise $[1,37]$.

Meta-analyses including studies from FGM/C practicing countries, and diaspora countries showed that FGM/C was significantly associated with prolonged labour [20,21], perineal tears, episiotomy, but not with caesarean section [21]. Obstetric outcomes coded in our study were mainly prolonged second stage of labour $(n=21)$ and perineal lacerations $(n=50)$ especially of first or second degree (90\%). 29 inpatients required a caesarean section, 14 an episiotomy, and 15 assistance during delivery.

Among 85,990 deliveries in 2017 in Swiss medical institutions, $54.7 \%$ of women had a perineal tear mainly of first or second degree $(94,7 \%) ; 32.3 \%$ a caesarean section; $11.1 \%$ an assisted delivery and, $17 \%$ an episiotomy [38]. In comparison, our data do not suggest high rates of obstetric complications in the studied population of women with a coded FGM/C. However we cannot draw any conclusion, because if common obstetric complications were likely correctly coded, FGM/C was undercoded [26]. 
A prospective study conducted in six African countries found a significant association between obstetric complications and FGM/C, especially type III [39]. However, retrospective studies from high-income countries such as Sweden, the UK, and Switzerland have shown that women with and without FGM/C have similar obstetric outcomes, likely because of overall quality and availability of obstetric care and specific management of FGM/C [40-42]. The relationship between FGM/C and obstetric complications is influenced by other factors than FGM/C alone. For example studies on the association between $\mathrm{FGM} / \mathrm{C}$ and caesarean section have shown different results: a Swiss and Australian studies found higher rates of caesarean sections among women with FGM/C compared with women from the general population without $\mathrm{FGM} / \mathrm{C}[43,44]$. One possible explanation was that health professionals unfamiliar with FGM/C could perform caesarean sections for inappropriate reasons, especially in case of infibulation [45]. In contrast, a retrospective study that included only Somalian women who delivered between 1990 and 2014 in Norway showed that women with FGM/C did not undergo more caesarean sections [46]. Migrant women in high-income countries often have higher rates of caesarean sections than non-migrants [47]. Communication barriers, economic difficulties, and exposure to violence have been found to result in poor maternal health and/or insufficient care quality for some migrants regardless of FGM/C [48-52].

Only five minor inpatients had an FGM/C code. Outpatient clinics may attend more children with $\mathrm{FGM} / \mathrm{C}$ than university hospitals, but paediatricians may also miss and/or not record it, because they lack knowledge on FGM/C, or rarely perform a genital examination [53-55]. Alternatively, abandonment of the practice could explain why few minors had an FGM/C code. A UK study confirmed 55 out of 148 suspected cases of FGM/C after referral to specialized clinics over four years, representing considerably fewer cases than previously suggested by UK prevalence estimates [14]. $21 \%$ of 55 children suffered from mental health symptoms such as anxiety, sleep and behaviour disorders, $13 \%$ from physical symptoms such as problems with micturition, menstruation and genital pain [14].

Except one post-traumatic stress disorder, mental health symptoms were not coded in our minor population, and rarely among adults. Swiss university hospitals' health professionals may lack time or training on how to detect and treat such symptoms and other FGM/C complications. Or, they may identify and manage psychophysical complications, without however identifying or documenting the FGM/C as an associated condition [54-60].

Coding of surgical interventions was incomplete. Perineal tears were more coded $(n=50)$ than perineal tears repairs $(n=8)$. Other repairs were either not coded, or coded as secondary interventions, which were not provided to us. Because no $\mathrm{CHOP}$ codes exist for defibulation and clitoral reconstruction, we had to hypothesize that codes such as repair $(n=5)$, or incision $(n=4)$ of vulva and perineum had been used to indicate these surgeries. Geneva provided the interventions' names instead of codes, and reported 8 clitoral surgeries and 4 defibulations among inpatients, and additionally reported 12 clitoral surgeries, 25 defibulations and 8 other surgeries for scar complications of FGM/C in outpatient care. Unfortunately some Swiss insurance companies have tried to refuse to reimburse these surgeries. Specific $\mathrm{CHOP}$ codes would facilitate medical coding and reimbursement.

Sensitisation and training of healthcare professionals and professional coders on FGM/C could improve identification, documentation and coding of FGM/C and its complications in Swiss university hospitals; inform and improve the quality of future policies, services and interventions.

\section{Conclusion}

Most of the 207 women and girls admitted to Swiss university hospitals between 2016 and 2018 with a primary or secondary diagnosis of $\mathrm{FGM} / \mathrm{C}$ were admitted to obstetrics divisions. Pregnancy and delivery seem to be key moments to care for and counsel a population that might not consult or be identified otherwise. FGM/C coding capacities in Swiss university hospitals are low, and some complications of FGM/C are probably not diagnosed, or diagnosed alone, without FGM/C.

\section{Abbreviations}

$\mathrm{CHOP}$

Swiss Classification of Surgical Interventions

CHUV

University Hospital of Lausanne

$\mathrm{FGM} / \mathrm{C}$

Female Genital Mutilation/Cutting

HUG 
Geneva University Hospitals

ICD

International Classification of Diseases

NHS

National Health System

USB

University Hospital of Basel

USZ

University Hospital of Zurich

UK

United Kingdom

$\mathrm{WHO}$

World Health Organization

\section{Declarations}

\section{Ethics approval}

This cross-sectional study was approved in December, 2018 by the Swiss Ethics Committees (SwissEthics) with the protocol number 2018-01851, and conducted according to the protocol, the Swiss legal requirements, and the World Medical Association Declaration of Helsinki. An exemption of informed consent was granted by the state of Geneva Swiss Ethics committee for the use of anonymized data extracted from the university hospitals databases.

\section{Consent for publication}

Not applicable.

\section{Availability of data and materials}

The datasets used and/or analysed during the current study available from the corresponding author on reasonable request.

\section{Competing interests}

No competing interests to declare.

\section{Funding}

Swiss Federal Office of Public Health, Swiss Network against Female Circumcision, Caritas Switzerland.

\section{Authors' contributions}

JA designed and directed the project. SCC collected the data, together with JA and MH. SCC did the data analysis, in collaboration with $\mathrm{MH}$. MH, SCC and JA wrote the manuscript. All the authors reviewed and approved the manuscript.

\section{Acknowledgements}

Swiss Network against Female Genital Cutting, Caritas Switzerland, and Swiss Federal Office of Public Health which funded the study.

Prof. Angèle-Gayet Ageron who suggested a data analysis plan.

\section{References}

1. World Health Organization. Care of women and girls living with female genital mutilation: a clinical handbook. Geneva: World Health Organization; 2018. https://www.who.int/reproductivehealth/publications/health-care-girls-women-living-with-FGM/en/. Accessed 14 Apr 2020. 
2. World Health Organization. Types of female genital mutilation [Internet]. Geneva: World Health Organization; c2021. https://mca.essensys.ro/teams/sexual-and-reproductive-health-and-research/key-areas-of-work/female-genital-mutilation/typesof-female-genital-mutilation. Accessed 17 Aug 2021.

3. UNICEF. Female Genita Mutilation/Cutting: a global concern. New York: UNICEF; 2016. https://data.unicef.org/resources/femalegenital-mutilationcutting-global-concern/. Accessed 17 Aug 2021.

4. UNICEF Data. Female Genital Mutilation (FGM) data [Internet]. New York: UNICEF; 2021. https://data.unicef.org/resources/dataset/fgm/. Accessed 17 Aug 2021.

5. Van Baelen L, Ortensi L, Leye E. Estimates of first-generation women and girls with female genital mutilation in the European Union, Norway and Switzerland. The European Journal of Contraception \& Reproductive Health Care. 2016;21(6):474-82.

6. Cottler-Casanova S, Abdulcadir J. Estimating the indirect prevalence of Female Genital Mutilation/Cutting in Switzerland. 2020.

7. Vogt S, Efferson C, Fehr E. The risk of female genital cutting in Europe: Comparing immigrant attitudes toward uncut girls with attitudes in a practicing country. SSM Popul Health. 2017;3:283-93.

8. Wahlberg A, Johnsdotter S, Ekholm Selling K, Källestål C, Essén B. Factors associated with the support of pricking (female genital cutting type IV) among Somali immigrants - a cross-sectional study in Sweden. Reproductive Health. 2017;14(1):92.

9. Wahlberg A, Johnsdotter S, Selling KE, Källestål C, Essén B. Baseline data from a planned RCT on attitudes to female genital cutting after migration: when are interventions justified? BMJ Open. 2017;7(8):e017506.

10. Wahlberg A, Johnsdotter S, Ekholm Selling K, Essén B. Correction: Shifting perceptions of female genital cutting in a Swedish migration context. PLoS One. 2020;15(2):e0229815-e.

11. Johnsdotter S, Mestre i Mestre RM. 'Female genital mutilation' in Europe: Public discourse versus empirical evidence. International Journal of Law, Crime and Justice. 2017;51:14-23.

12. Cappa C, Van Baelen L, Leye E. The practice of female genital mutilation across the world: Data availability and approaches to measurement. Glob Public Health. 2019;14(8):1139-52.

13. De Schrijver L, Van Baelen L, Van Eekert N, Leye E. Towards a better estimation of prevalence of female genital mutilation in the European Union: a situation analysis. Reproductive Health. 2020;17(1):105.

14. Ali S, Patel R, Armitage AJ, Learner HI, Creighton SM, Hodes D. Female genital mutilation (FGM) in UK children: a review of a dedicated paediatric service for FGM. Arch Dis Child. 2020;105(11):1075-8.

15. Hodes D, Ayadi O'Donnell N, Pall K, Leoni M, Lok W, Debelle G, et al. Epidemiological surveillance study of female genital mutilation in the UK. Arch Dis Child. 2020.

16. Ortensi LE, Menonna A. Migrating with Special Needs? Projections of Flows of Migrant Women with Female Genital Mutilation/Cutting Toward Europe 2016-2030. Eur J Popul. 2017;33(4):559-83.

17. United Nations Population Fund. Female genital mutilation [Internet]. New York: United Nations Population Fund; c2021. https://www.unfpa.org/female-genital-mutilation. Accessed 18 May 2021.

18. World Health Organization Department of Sexual and Reproductive Health and Research. Female Genital Mutilation Cost Calculator [Internet]. Geneva: World Health Organization; c2020. https://srhr.org/fgmcost/. Accessed 16 May 2021.

19. Berg RC, Underland V, Odgaard-Jensen J, Fretheim A, Vist GE. Effects of female genital cutting on physical health outcomes: a systematic review and meta-analysis. BMJ Open. 2014;4(11):e006316.

20. Berg RC, Odgaard-Jensen J, Fretheim A, Underland V, Vist G. An Updated Systematic Review and Meta-Analysis of the Obstetric Consequences of Female Genital Mutilation/Cutting. Obstetrics and Gynecology International. 2014;2014:8.

21. Lurie JM, Weidman A, Huynh S, Delgado D, Easthausen I, Kaur G. Painful gynecologic and obstetric complications of female genital mutilation/cutting: A systematic review and meta-analysis. PLoS Med. 2020;17(3):e1003088.

22. Elmusharaf S, Elhadi N, Almroth L. Reliability of self reported form of female genital mutilation and WHO classification: cross sectional study. BMJ. 2006;333(7559):124.

23. Ministry of Health (MOH) [Maldives] and ICF. 2018. Maldives Demographic and Health Survey 2016-17. Malé, Maldives, and Rockville, Maryland, USA: MOH and ICF. http://dhsprogram.com/pubs/pdf/FR349/FR349.pdf. Accessed 14 Apr 2021.

24. Federal Statistical Office. Medical classification and coding [Internet]. Neuchâtel: Federal Statistical Office; 2021. https://www.bfs.admin.ch/bfs/fr/home/statistiques/sante/nomenclatures/medkk.html. Accessed 20 Apr 2021. 
25. Cottler-Casanova S, Horowicz M, Gieszl S, Johnson-Agbakwu C, Abdulcadir J. Coding female genital mutilation/cutting and its complications using the International Classification of Diseases: a commentary. BJOG. 2020;127(6):660-4.

26. Cottler-Casanova S, Horowicz M, Gayet-Ageron A, Abdulcadir J. Female genital mutilation/cutting (FGM/C) coding capacities in Swiss university hospitals using the International Classification of Diseases (ICD). BMC Public Health. 2021;21(1):1151.

27. HUG. Key numbers 2016 [Internet]. 2021. https://www.hug.ch/chiffres-cles-2016/soins. Accessed 20 Apr 2021.

28. HUG. Key numbers 2017 [Internet]. 2021. https://www.hug.ch/chiffres-cles-2017/soins. Accessed 20 Apr 2021.

29. HUG. Key numbers 2018 [Internet]. 2021. https://www.hug.ch/chiffres-cles-2018/activite-medicale. Accessed 20 Apr 2021.

30. CHUV. The CHUV in numbers [Internet]. 2021. https://www.chuv.ch/fr/chuv-home/en-bref/chiffres. Accessed 20 Apr 2021.

31. Inselspital Frauenklinik. Annual report 2016 [Internet]. 2016.

http://www.frauenheilkunde.insel.ch/fileadmin/Frauenheilkunde/05_Ueber_uns/20170513_Jahresbericht_Frauenklinik_2016.pdf. Accessed 20 Apr 2021.

32. Inselspital Frauenklinik. Annual report 2018 [Internet]. 2018.

http://www.frauenheilkunde.insel.ch/fileadmin/Frauenheilkunde/05_Ueber_uns/20190915_Jahresbericht_Frauenklinik_2018.pdf. Accessed 20 Apr 2021.

33. Universitätsspital Zürich. Annual report of the clinic for obstetrics. [Internet]. 2021. https://new.usz.ch/fachbereich/geburtshilfe/ueber-uns/jahresberichte/. Accessed 20 Apr 2021.

34. Federal Statistical Office. Living births according to canton and nationality category of the mother Federal Statistical Office [Internet]. Neuchâtel: Federal Statistical Office; 2020. https://www.bfs.admin.ch/bfs/en/home/statistics/population/birthsdeaths/births.assetdetail.13187404.html. Accessed 20 Apr 2021.

35. Federal Chancellery. ch.ch. Pregnancy - what health insurance covers [Internet]. c2013. https://www.ch.ch/en/pregnancy-healthinsurance-covers/. Accessed 20 Apr 2021.

36. NHS Digital. Female Genital Mutilation (FGM) Enhanced Dataset October 2020 to December 2020, England, experimental statistics [Internet]. Leeds: NHS Digital; 2021 https://files.digital.nhs.uk/FA/A4FA2A/Female\%20Genital\%20Mutilation\%20\%28FGM\%29\%20\%200ctober\%20to\%20December\%202020\%20-\%20Report.pdf. Accessed 20 Apr 2021.

37. World Health Organization. WHO recommendations on antenatal care for a positive pregnancy experience. Geneva: World Health Organization; 2016 https://www.who.int/publications/i/item/9789241549912. Accessed 7 Jul 2021.

38. Federal Statistical Office. Deliveries and maternal health in 2017. Neuchâtel: Federal Statistical Office; 2017. https://www.bfs.admin.ch/bfs/en/home/news/whats-new.assetdetail.8288948.html. Accessed 20 Apr 2021.

39. WHO study group on female genital mutilation and obstetric outcome. Female genital mutilation and obstetric outcome: WHO collaborative prospective study in six African countries. The Lancet. 2006;367(9525):1835-41.

40. Essen B, Bodker B, Sjoberg NO, Gudmundsson S, Ostergren PO, Langhoff-Roos J. Is there an association between female circumcision and perinatal death? Bulletin of the World Health Organization. 2002;80(8):629-32.

41. Balachandran AA, Duvalla $S$, Sultan $A H$, Thakar R. Are obstetric outcomes affected by female genital mutilation? Int Urogynecol J. 2018;29(3):339-44.

42. Abdulcadir J, Dugerdil A, Yaron M, Irion O, Boulvain M. Obstetric care of women with female genital mutilation attending a specialized clinic in a tertiary center. Int J Gynaecol Obstet. 2016;132(2):174-8.

43. Wuest S, Raio L, Wyssmueller D, Mueller MD, Stadlmayr W, Surbek DV, et al. Effects of female genital mutilation on birth outcomes in Switzerland. BJOG. 2009;116(9):1204-9.

44. Varol N, Dawson A, Turkmani S, Hall JJ, Nanayakkara S, Jenkins G, et al. Obstetric outcomes for women with female genital mutilation at an Australian hospital, 2006-2012: a descriptive study. BMC Pregnancy Childbirth. 2016;16(1):328.

45. Rodriguez MI, Say L, Abdulcadir J, Hindin MJ. Clinical indications for cesarean delivery among women living with female genital mutilation. International Journal of Gynecology \& Obstetrics. 2017;139(1):21-7.

46. Taraldsen S, Vangen S, Oian P, Sorbye IK. Female genital mutilation/cutting, timing of deinfibulation, and risk of cesarean section. Acta Obstet Gynecol Scand. 2021;100(4):587-95.

47. Merry L, Vangen S, Small R. Caesarean births among migrant women in high-income countries. Best Pract Res Clin Obstet Gynaecol. 2016;32:88-99.

Page $24 / 25$ 
48. Essen B, Johnsdotter S, Hovelius B, Gudmundsson S, Sjoberg NO, Friedman J, et al. Qualitative study of pregnancy and childbirth experiences in Somalian women resident in Sweden. BJOG. 2000;107(12):1507-12.

49. Scamell M, Ghumman A. The experience of maternity care for migrant women living with female genital mutilation: A qualitative synthesis. Birth. 2019;46(1):15-23.

50. Binkova A, Uebelhart M, Dallenbach P, Boulvain M, Gayet-Ageron A, Abdulcadir J. A cross-sectional study on pelvic floor symptoms in women living with Female Genital Mutilation/Cutting. Reprod Health. 2021;18(1):39.

51. Fox KA, Johnson-Agbakwu C. Crime Victimization, Health, and Female Genital Mutilation or Cutting Among Somali Women and Adolescent Girls in the United States, 2017. Am J Public Health. 2020;110(1):112-8.

52. Ziyada MM, Lien IL, Johansen REB. Sexual norms and the intention to use healthcare services related to female genital cutting: A qualitative study among Somali and Sudanese women in Norway. PLoS One. 2020;15(5):e0233440.

53. Young J, Nour NM, Macauley RC, Narang SK, Johnson-Agbakwu C, Section On Global H, et al. Diagnosis, Management, and Treatment of Female Genital Mutilation or Cutting in Girls. Pediatrics. 2020;146(2).

54. Sureshkumar P, Zurynski Y, Moloney S, Raman S, Varol N, Elliott EJ. Female genital mutilation: Survey of paediatricians' knowledge, attitudes and practice. Child Abuse \& Neglect. 2016;55:1-9.

55. Young J, Rodrigues KK, Imam B, Johnson-Agbakwu C. Female Genital Mutilation/Cutting-Pediatric Physician Knowledge, Training, and General Practice Approach. J Immigr Minor Health. 2019.

56. Abdulcadir J, Dugerdil A, Boulvain M, Yaron M, Margairaz C, Irion O, et al. Missed opportunities for diagnosis of female genital mutilation. International Journal of Gynecology \& Obstetrics. 2014;125(3):256-60.

57. González-Timoneda A, Ruiz Ros V, González-Timoneda M, Cano Sánchez A. Knowledge, attitudes and practices of primary healthcare professionals to female genital mutilation in Valencia, Spain: are we ready for this challenge? BMC health services research. 2018;18(1):579-.

58. Tantet C, Aupiais C, Bourdon M, Sorge F, Pages A, Levy D, et al. Female genital mutilation: an evaluation of the knowledge of French general and specialized travel medicine practitioners. J Travel Med. 2018;25(1).

59. Zurynski Y, Sureshkumar P, Phu A, Elliott E. Female genital mutilation and cutting: a systematic literature review of health professionals' knowledge, attitudes and clinical practice. BMC International Health and Human Rights. 2015;15(1):32.

60. Fay KE, Snead CM, Huennekens K, O'Brian CA, Tom L, Simon MA. United States' Obstetrician/Gynecologists' Readiness to Care for Women Affected by Female Genital Cutting. J Womens Health (Larchmt). 2021. 